\title{
Biological Effects of the Novel Mulberry Surface Characterized by Micro/Nanopores and Plasma-Based Graphene Oxide Deposition on Titanium
}

\author{
Hee-Seon Kim ${ }^{1} *$ \\ Min-Kyung $\mathrm{Ji}^{2}, *$ \\ Woo-Hyung Jang $\mathbb{D D}^{1, *}$ \\ Khurshed Alam (D) ${ }^{3}$ \\ Hyun-Seung $\mathrm{Kim}^{4}$ \\ Hoon-Sung Cho $\mathbb{D D}^{3}$ \\ Hyun-Pil Lim'
}

'Department of Prosthodontics, School of Dentistry, Chonnam National University, Gwangju, Republic of Korea; ${ }^{2}$ Optoelectronics Convergence Research Center, Chonnam National University, Gwangju, 6II86, Republic of Korea; ${ }^{3}$ Department of Materials Science and Engineering, Chonnam National University, Gwangju, 6I I86, Republic of Korea; ${ }^{4}$ Department of Division of New Projects, KJ Meditech Co, Ltd, Gwangju, 61009, Republic of Korea

*These authors contributed equally to this work

Correspondence: Hyun-Pil Lim Department of Prosthodontics, School of Dentistry, Chonnam National University, Gwangju, 61 I86, Republic of Korea

Tel +82-10-2645-7528

Fax +82-62-530-5577

Email mcnihil@jnu.ac.kr

Hoon-Sung Cho

Department of Materials Science and Engineering, Chonnam National

University, Gwangju, 6II86, Republic of Korea

Tel +82-10-8545-2816

Fax +82-62-530-1717

Email cho.hoonsung@jnu.ac.kr
Purpose: This paper presents a technique for developing a novel surface for dental implants using a combination of nitriding and anodic oxidation, followed by the deposition of graphene oxide using atmospheric plasma. The effects of various surface treatments on bacterial adhesion and osteoblast activation were also evaluated.

Methods: CP titanium (control) was processed into disk-shaped specimens. Nitriding was conducted using vacuum nitriding, followed by anodic oxidation, which was performed in an electrolyte using a DC power supply, to form the novel "mulberry surface." Graphene oxide deposition was performed using atmospheric plasma with an inflow of carbon sources. After analyzing the sample surfaces, antibacterial activity was evaluated using Streptococcus mutans and Porphyromonas gingivalis bacteria. The viability, adhesion, proliferation, and differentiation of osteoblasts were also assessed. Analysis of variance (ANOVA) with Tukey's post-hoc test was used to calculate statistical differences.

Results: We observed that the mulberry surface was formed on samples treated with nitriding and anodic oxidation, and these samples exhibited more effective antibacterial activity than the control. We also found that the samples with additional graphene oxide deposition exhibited better biocompatibility, which was validated by osteoblast adhesion, proliferation, and differentiation.

Conclusion: The development of the mulberry surface along with graphene oxide deposition inhibits bacterial adhesion to the implant and enhances the adhesion, proliferation, and differentiation of osteoblasts. These results indicate that the mulberry surface and graphene oxide deposition together can inhibit peri-implantitis and promote osseointegration.

Keywords: nitriding, anodic oxidation, atmospheric plasma, biofilm formation, osteoblasts

\section{Introduction}

Titanium has been widely used as a dental implant material to replace missing teeth because of high biocompatibility and osseointegration. ${ }^{1}$ However, failures in dental implant therapy are related to a lack of stability at the implant abutment interface, occurrence of bacterial infections, and failure of the osseointegration process. ${ }^{2}$ Moreover, changes in the chemical composition and surface roughness of titanium implants have been reported to affect osseointegration as well as antibacterial activity. ${ }^{3,4}$

Nitriding the surface of titanium results in high biocompatibility; hence, such surface treatments of biomaterials have received great attention. Furthermore, in 
some of our previous studies, we reported that the adhesion of Streptococcus mutans to the titanium surface was reduced by the presence of a TiN layer. ${ }^{5-7}$ On the other hand, anodic oxidation can form a film composed of amorphous $\mathrm{TiO}_{2}$ that is electrochemically porous. The surface area of the film can be increased by changing the underlying crystal structure or by regulating the thickness or surface roughness of the film, which in turn can improve cell viability, adhesion, proliferation, and differentiation. ${ }^{8,9}$ Moreover, surfaces with micropores and nanopores have been reported to be advantageous for osteoblast viability, adhesion, and proliferation. ${ }^{10,11}$ In this study, we developed a novel titanium surface that we refer to as the "mulberry surface," which contains both micropores and nanopores and was obtained by nitriding titanium followed by anodic oxidation.

Graphene oxide, which is an allotrope of carbon with hexagonal symmetry, has been under the spotlight in various fields as a nanomaterial having a large surface area and superior physical, chemical, and biological properties. $^{12}$ Graphene oxide is typically synthesized using chemical vapor deposition and Hummer's method. ${ }^{13-15}$ However, it requires additional treatment for application onto the surface of materials. Therefore, in this study, we developed an innovative method to deposit graphene oxide on the surface of titanium using atmospheric plasma. ${ }^{16}$ Note that the atmospheric plasma decomposes the carbon molecules into carbon atoms as it flows through the plasma flame and generates graphene oxide. Plasma-based graphene oxide deposition on titanium has been known to enhance biocompatibility as well as the viability and differentiation of osteoblasts. ${ }^{15}$

In this study, the titanium surface was first nitrided and then subjected to anodic oxidation to form the aforementioned mulberry surface. Next, graphene oxide was deposited on this surface. Finally, we evaluated the characteristics, antibacterial properties, and osteoblast viability on the new surface.

\section{Materials and Methods}

\section{Experimental Materials}

\section{Samples}

Commercial pure titanium (ASTM Grade IV, Kobe Steel, Japan) was cleaned and processed into disks (diameter: $15 \mathrm{~mm}$, thickness: $3 \mathrm{~mm}$ ) and subjected to surface treatment to generate the samples for our experiments, as shown in Table 1 .
Table I Treatment Groups in the Experiment

\begin{tabular}{|l|c|}
\hline Group & Condition \\
\hline Control & No treatment \\
N & Nitriding \\
NA & Nitriding + Anodic oxidation \\
NAG & Nitriding + Anodic oxidation + Graphene oxide \\
\hline
\end{tabular}

\section{Nitriding Conditions}

The nitride layer on the titanium surface was formed using vacuum nitriding (Mirae-2VF600, Thermotec, Korea). The disks were heat-treated at a temperature in the range of $600-800^{\circ} \mathrm{C}$, and $\mathrm{N}_{2}$ gas was injected under vacuum at $1020^{\circ} \mathrm{C}$ for $4 \mathrm{~h}$. Next, the disks were cooled at a pressure of 6 bar to form the nitriding layer.

\section{Anodic Oxidation}

Anodic oxidation of the porous surface was performed using a DC power supply (Fine Power F-3005, Korea). We prepared the electrolyte used in this study by adding $1 \mathrm{M}$ phosphoric acid solution (Sigma-Aldrich, USA) and $1.5 \mathrm{wt} \%$ hydrofluoric acid solution (Sigma-Aldrich) to distilled water. Titanium and platinum disks were connected to the cathode and anode, respectively, and the sample was placed approximately $10 \mathrm{~mm}$ from the platinum disk. A voltage of $20 \mathrm{~V}$ was applied, and the connected titanium and platinum disks were deposited in the electrolyte for $1 \mathrm{~min}$. After $60 \mathrm{~min}$, the sample was removed from the electrolyte and cleaned under running water for approximately $30 \mathrm{~min}$. Next, the sample was deposited in distilled water for $1 \mathrm{~h}$, after which it was dried.

\section{Graphene Oxide Deposition}

Graphene oxide was deposited on the titanium samples using an atmospheric-pressure plasma generator (PGS-300 Expantect, Korea). Argon gas (4 L/min) and methane gas $(3.5 \mathrm{~mL} / \mathrm{min}$ ) were mixed and introduced into a quartz tube, and the graphene oxide was coated onto the samples at 300 W using a high-frequency (900 MHz) plasma generator. The distance between the plasma flame and the sample was maintained at $15 \mathrm{~mm}$. Furthermore, the plasma flame was applied to the sample uniformly for $6 \mathrm{~min}$ while the sample was simultaneously rotated at $180 \mathrm{rpm}$ and the flame was rotated from side to side (see Table 2 for details).

\section{Assessment of Surface Characteristics}

The thickness at 3 points of each specimen was measured before and after surface treatment using a Vernier caliper (MT-500-181-300, Mitutoyo, Korea) to obtain an average value. The formation of micropores and nanopores and the 
Table 2 Parameters of the Atmospheric Plasma Generator

\begin{tabular}{|l|c|}
\hline Parameter & Value \\
\hline Average working power (W) & 300 \\
Voltage (V) & 27 \\
Frequency (MHz) & 900 \\
Atmospheric pressure (Torr) & 760 \\
Cooling type & Air cooled \\
Plasma density & $10^{15} / \mathrm{cm}^{3}$ \\
\hline
\end{tabular}

surface structure of the samples with graphene oxide deposition were analyzed using a Field Emission Scanning Electron Microscope (FE-SEM; S-4700, Hitachi, Japan). Raman Spectroscopy of the sample was performed to determine the status of graphene oxide deposition using a laser Raman Spectrophotometer (NRS-5100, JASCO, Korea) at a laser excitation of $532.13 \mathrm{~nm}$. The chemical composition and bonding energy of graphene oxide were analyzed using X-ray Photoelectron Spectroscopy (XPS; MultiLab 2000, Thermo Electron Corporation, England). The surface roughness of the samples as a result of various treatments was observed using a non-contact nanosurface 3D Optical Profiler (OP; NV-E1000, Nano System, Korea). In each sample, three areas were measured, and their average roughness or $\mathrm{Ra}$ values were calculated. Wettability, a critical factor for biocompatibility, was determined via contact angle measurements using a Video Contact Angle measuring device (Phoenix 300, SEO, Korea). Distilled water $(4 \mu \mathrm{L})$ was dropped on the surface of the sample, and after $10 \mathrm{~s}$, the angle between the surface and the solution was measured, and their average was calculated (Surfaceware 9 software ${ }^{\circledR}$, SEO).

\section{Assessment of Bacterial Activity Bacterial Cultures}

Streptococcus mutans (KCOM 1054, Gwangju, Korea), a gram-positive bacterium known to be involved in the early stage of biofilm formation, and Porphyromonas gingivalis (KCOM 2804, Gwangju, Korea), a gram-negative anaerobic bacterium known to cause peri-implantitis, were obtained from the Korean Collection for Oral Microbiology (KCOM). S. mutans strains were cultured at $37^{\circ} \mathrm{C}$ in a culture chamber (LIB-150M, DAIHAN Labtech Co., Namyangju, Korea) using a brain-heart infusion (BHI; Becton, Dickinson and Company, Sparks, MD, USA) medium. $P$. gingivalis strains were also cultured at $37^{\circ} \mathrm{C}$ in an anaerobic culture chamber (Forma Anaerobic
System 1029; Thermo Fisher Scientific, Waltham, MA, USA) using tryptic soy broth (Becton, Dickinson and Company, Sparks, MD, USA).

\section{Bacterial Inoculation}

All samples were sterilized in an autoclave (HS-3460SD, Hanshin Medical Co., Korea) for $2 \mathrm{~h}$. The samples for each group were prepared and fixed on a 24-well plate (SPL Life Sciences Co., Ltd., Korea). Each sample was inoculated with $S$. mutans and $P$. gingivalis $\left(1.5 \times 10^{7}\right.$ $\mathrm{CFU} / \mathrm{mL}$ ) and cultured for 24 and $48 \mathrm{~h}$, respectively.

\section{Bacterial Adhesion Assessment Crystal Violet Staining Assay}

The degree of bacterial adhesion was analyzed by crystal violet staining. After bacterial culturing, the culture medium was removed and the samples were cleaned twice using phosphate-buffered saline (PBS) solution. The bacteria adhering to the samples were dyed by dispensing $500 \mu \mathrm{L}$ of $0.3 \%$ crystal violet solution. After $10 \mathrm{~min}$, the crystal violet solution was removed, and the remaining sample was cleaned thrice with PBS. The samples were then dried for 15 min, after which $500 \mu \mathrm{L}$ of demineralized solution $(80 \%$ ethyl alcohol $+20 \%$ acetone) was dispensed. To ensure that the solution did not volatilize, it was tightly sealed and stirred for $1 \mathrm{~h}$. Next, $200 \mu \mathrm{L}$ of each sample was dispensed into a 96-well plate (SPL Life Sciences Co., Ltd) and its absorbance was measured at a wavelength of $595 \mathrm{~nm}$ using a VersaMax ELISA Microplate Reader (Molecular Devices, Sunnyvale, CA, USA).

\section{Assessment of Osteoblast Viability Cell Culture}

MC3T3-E1 (MC3T3-E1 subclone 4, ATCC CRL2593, USA), an osteoblast cell line, was cultured at $37^{\circ} \mathrm{C}$ in a $5 \%$ $\mathrm{CO}_{2}$ incubator (Forma Series II3111 Water Jacketed $\mathrm{CO}_{2}$ Incubator, Thermo Fisher Scientific). $\alpha$-Minimum Essential Medium (Dulbecco's modified Eagle's medium, Gibco-BRL, Grand Island, NY, USA) was used with $10 \%$ fetal bovine serum and $1 \%$ penicillin.

\section{Cytotoxicity Assessment}

To evaluate cell adhesion, we fixed ten samples from each group on a 24-well plate. A solution of cultured cells with a concentration of $4 \times 10^{4}$ cells $/ \mathrm{mL}$ was dispensed onto the sample. The cells were cultured at $37^{\circ} \mathrm{C}$ in a $5 \% \mathrm{CO}_{2}$ incubator. Cell adhesion was evaluated after $24 \mathrm{~h}$ of incubation, whereas cell proliferation was evaluated on the fifth day after the cells were dispensed. Cell adhesion 
and proliferation were analyzed using a WST-8 assay kit (EZ-Cytox, Itsbio, Inc., Korea). Each well in the plate received $100 \mu \mathrm{L}$ of WST-8 solution, which was cultured again at $37^{\circ} \mathrm{C}$ in a $5 \% \mathrm{CO}_{2}$ incubator. After $1 \mathrm{~h}$, when the color of the samples turned orange, the suspension in each well $(100 \mu \mathrm{L})$ was dispensed into a 96-well plate, and its absorbance was measured at a wavelength of $450 \mathrm{~nm}$ using a VersaMax ELISA microplate reader (Molecular Devices).

\section{Fluorescent Staining Images of Cell} LIVE/DEAD ${ }^{\mathrm{TM}}$ Viability/Cytotoxicity Kit, for mammalian cells (USA, cat no. L3224) was used for the visual assessment of cell adhesion and proliferation. Cultured cells at a concentration of $4 \times 10^{4}$ cells $/ \mathrm{mL}$ were dispensed onto each specimen and incubated in a $\mathrm{CO}_{2}$ incubator set to $5 \%$ $\mathrm{CO}_{2}$ and $37^{\circ} \mathrm{C}$ for 24 and $48 \mathrm{~h}$. The cells were then stained using a LIVE/DEAD Viability/Cytotoxicity Kit (Thermo Fisher Scientific) at $37^{\circ} \mathrm{C}$ for $30 \mathrm{~min}$. At each time point, the cells were washed thrice with PBS, and then were stained for $30 \mathrm{~min}$ using $200 \mu \mathrm{L}$ of a fluorescent reagent (AM: ethidium homodimer-1: $\mathrm{dH}_{2} \mathrm{O}=0.5 \mu \mathrm{L}: 2 \mu \mathrm{L}$ : $1 \mathrm{~mL}$ ). Then, after washing the specimen thrice with PBS, cell adhesion and proliferation were analyzed using a confocal laser scanning microscope (Leica TCS SP5 AOBS/tandem, Leica Microsystems, Bensheim, Germany).

\section{Cellular Differentiation Assessment}

Cell differentiation was evaluated using 10 samples from each group, fixed on a 24-well plate. A solution of cultured cells with a concentration of $1 \times 10^{4}$ cells $/ \mathrm{mL}$ was dispensed onto the sample (the cells were cultured at $37^{\circ} \mathrm{C}$ in a $5 \% \mathrm{CO}_{2}$ incubator).

\section{Alkaline Phosphatase (ALP) Assay}

Cell differentiation was evaluated on the twenty-first day after the cells were dispensed and analyzed using the ALP assay. Each well was filled with $200 \mu \mathrm{L}$ of the ALP assay solution, which was cultured at $37^{\circ} \mathrm{C}$ in a $5 \% \mathrm{CO}_{2}$ incubator. After $1 \mathrm{~h}, 80 \mu \mathrm{L}$ of the suspension in each well was transferred into a 96-well plate, which was then treated with $50 \mu \mathrm{L}$ of p-Nitrophenyl Phosphate (pNPP) solution. Next, this sample was incubated again at $37^{\circ} \mathrm{C}$ in a $5 \%$ $\mathrm{CO}_{2}$ chamber for $1 \mathrm{~h}$. Subsequently, the sample was treated with $20 \mu \mathrm{L}$ of stop solution, and its absorbance was measured at $405 \mathrm{~nm}$ using a VersaMax ELISA Microplate Reader (Molecular Devices).

\section{Statistical Analysis}

Statistical analysis was conducted using SPSS software (version 21.0; SPSS Inc., Chicago, IL, USA). When the assumption of normality was met in the Shapiro-Wilk test, a one-way analysis of variance (ANOVA) with Tukey's post-hoc test was performed. The results were considered statistically significant when the significance level was $95 \%$, and the p-value was less than 0.05 .

\section{Results}

\section{Surface Characteristics}

The thickness of specimens of all groups before surface treatment was constant at $3 \mathrm{~mm}$. In comparison, after surface treatment, the thickness of specimens without any treatment (control) was $3 \mathrm{~mm}$; the thickness of group "N," coated with a nitride layer changed due to the nitride layer deposition and was confirmed to be $3.02 \mathrm{~mm}$; in group "NA", a slightly higher thickness was confirmed at $3.05 \mathrm{~mm}$ due to the nitride layer and $1 \mathrm{~h}$ anodization treatment; in group "NAG", it was confirmed that the thickness was increased to $3.07 \mathrm{~mm}$ due to the nitride layer coating, anodization, and graphene oxide deposition, and this group showed deposition of the thickest layer of all groups. The nitride layer on the titanium surface was treated with an electrolyte composed of $1 \mathrm{M}$ of $\mathrm{H}_{2} \mathrm{PO}_{4}$ and $1.5 \mathrm{wt} \% \mathrm{HF}$, and anodic oxidation was performed at $20 \mathrm{~V}$ for $60 \mathrm{~min}$. This resulted in the formation of a novel mulberry surface with both micropores and nanopores. The FE-SEM analysis results (Figure 1) revealed a mechanically processed surface in the control group (Figure 1A); no micropores or nanopores were created in group $\mathrm{N}$ coated with a nitride layer (Figure 1B). Group NA (Figure 1C), which was subjected to both nitriding and anodic oxidation, exhibited a mulberry surface with a combination of micropores (average size: 50-100 $\mu \mathrm{m}$ ) and nanopores (average size: $25-30 \mathrm{~nm}$ ). In group NAG (Figure 1D), additional nanolayers of graphene oxide were deposited on the porous surface that were clustered and in the form of clouds, as revealed by Raman spectroscopy.

Raman spectroscopy revealed the unique peaks of graphene oxide (D band at $\sim 1350 \mathrm{~cm}^{-1}, \mathrm{G}$ band at $\sim 1590 \mathrm{~cm}^{-1}$, and 2D band at $\sim 2580 \mathrm{~cm}^{-1}$ ) in group NAG, which was subjected to graphene oxide deposition (see Figure 2). This confirms that graphene oxide was deposited on the titanium surface. 


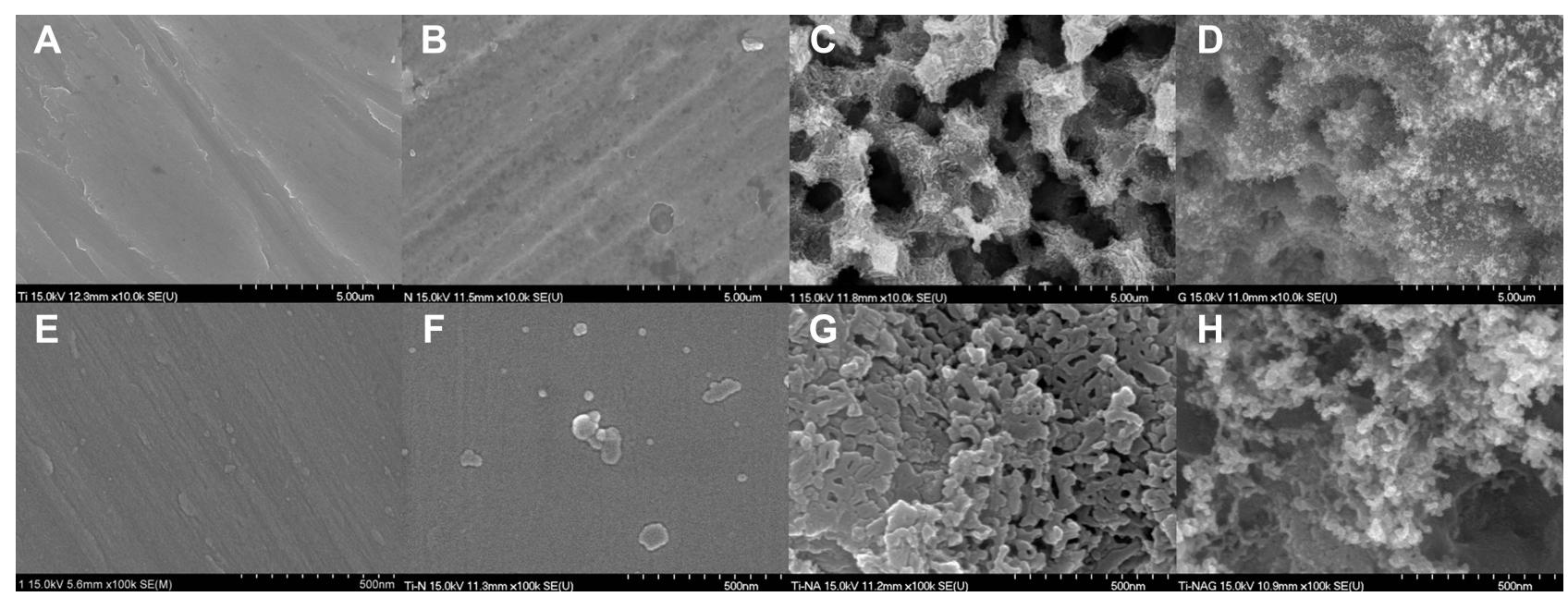

Figure I FE-SEM images of the titanium samples in: (A) the control group; (B) Group N containing only a nitride layer; (C) Group NA subjected to both nitriding and anodic oxidation; and (D) Group NAG subjected to nitriding, anodic oxidation, and graphene oxide deposition (I0,000x FE-SEM mode). (E) the control group; (F) Group $\mathrm{N}$ containing only a nitride layer; $(\mathbf{G})$ Group NA subjected to both nitriding and anodic oxidation; and $(\mathbf{H})$ Group NAG subjected to nitriding, anodic oxidation, and graphene oxide deposition (100,000x FE-SEM mode).

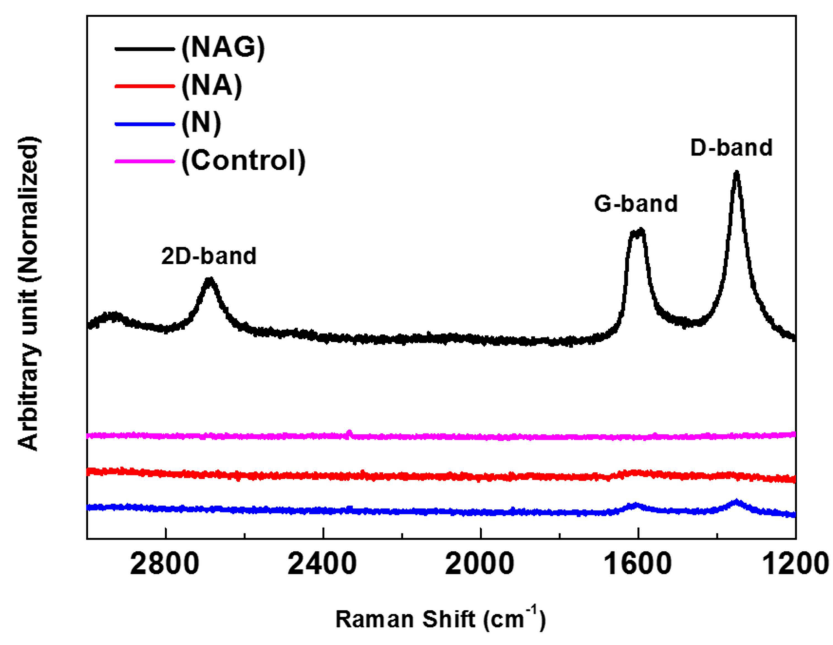

Figure 2 Raman spectrum of the graphene oxide layer generated on the titanium surface confirming that the deposited carbon film was composed of graphene oxide.

In the XPS analysis, Ti (2p1), O (1s), and C (1s) electrons were detected in all samples; in addition, $\mathrm{N}$ (1s) electrons were detected in groups $\mathrm{N}, \mathrm{NA}$, and NAG. In group N, the intensity of the $\mathrm{N}$ (1s) peak increased after nitriding was performed. In group NA, the intensity of the $\mathrm{N}$ (1s) peak decreased, while that of the $\mathrm{C}$ (1s) peak increased after anodic oxidation. In group NAG, the intensity of the C (1s) peak was three-fold greater than that in group NA because of graphene oxide deposition (Figure 3). In the XPS analysis of group NA with anodization treatment and group NAG with both anodization treatment and graphene oxide deposition, we were unable to examine the nitride layers due to thin nitride layers and the resulting weak TiN peaks.
The surface roughness of each treatment group was obtained from the 3D-OP analysis and was found to be $0.03,0.05,3.2$, and $4.2 \mu \mathrm{m}$ for the control group and groups N, NA, and NAG, respectively. Thus, the control group showed the lowest roughness, whereas the samples in the NAG group had the highest roughness (Figure 4). The regulation of surface roughness in specimens with graphene oxide deposition was not separately studied. We prioritized the study of cell compatibility and focused on the optimal coating type for cell compatibility.

The water contact angles of the samples were $53.27^{\circ}$, $60.72^{\circ}, 62.93^{\circ}$, and $125.48^{\circ}$ for the control group and groups N, NA, and NAG, respectively. Thus, the control group, groups $\mathrm{N}$, and NA showed a hydrophilic tendency, whereas group NAG showed a hydrophobic tendency (Figure 5).

\section{Inhibition of Biofilm Formation}

The crystal violet assay results showed that the adhesion of $S$. mutans to the samples in Groups NA and NAG decreased significantly compared to that in the control group; moreover, the adhesion in Groups NA and NAG was reduced compared to that in Group N. The adhesion of $P$. gingivalis to the samples in Group NAG also decreased significantly compared to adhesion in the control group and Groups N and NA (Figure 6). These results indicate that Groups NA and NAG exhibited stronger antibacterial activity than the control group by inhibiting the adhesion of $S$. mutans and $P$. gingivalis. Considering 

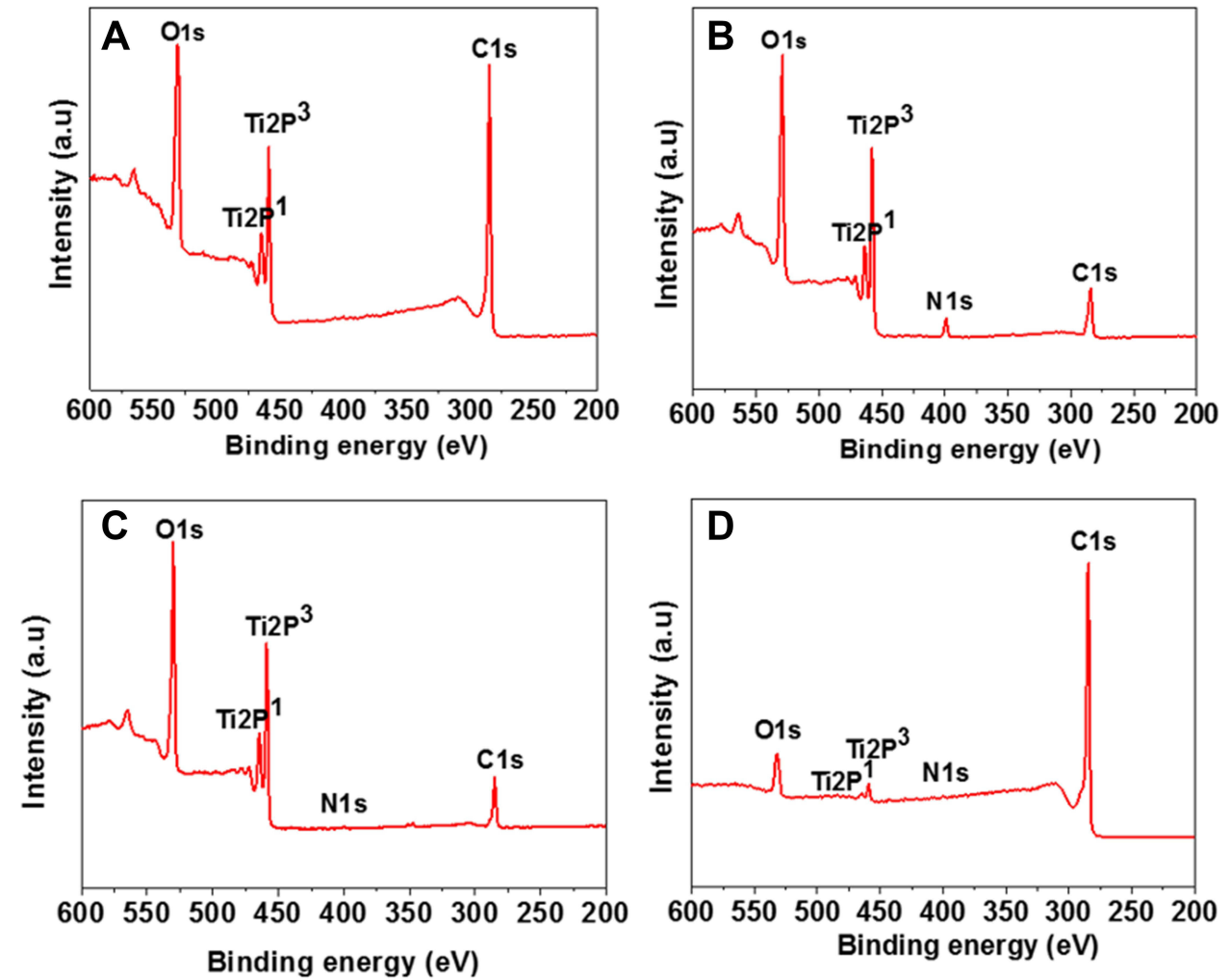

Figure 3 XPS spectra of the titanium samples in: (A) the control group; (B) Group N; (C) Group NA; and (D) Group NAG.
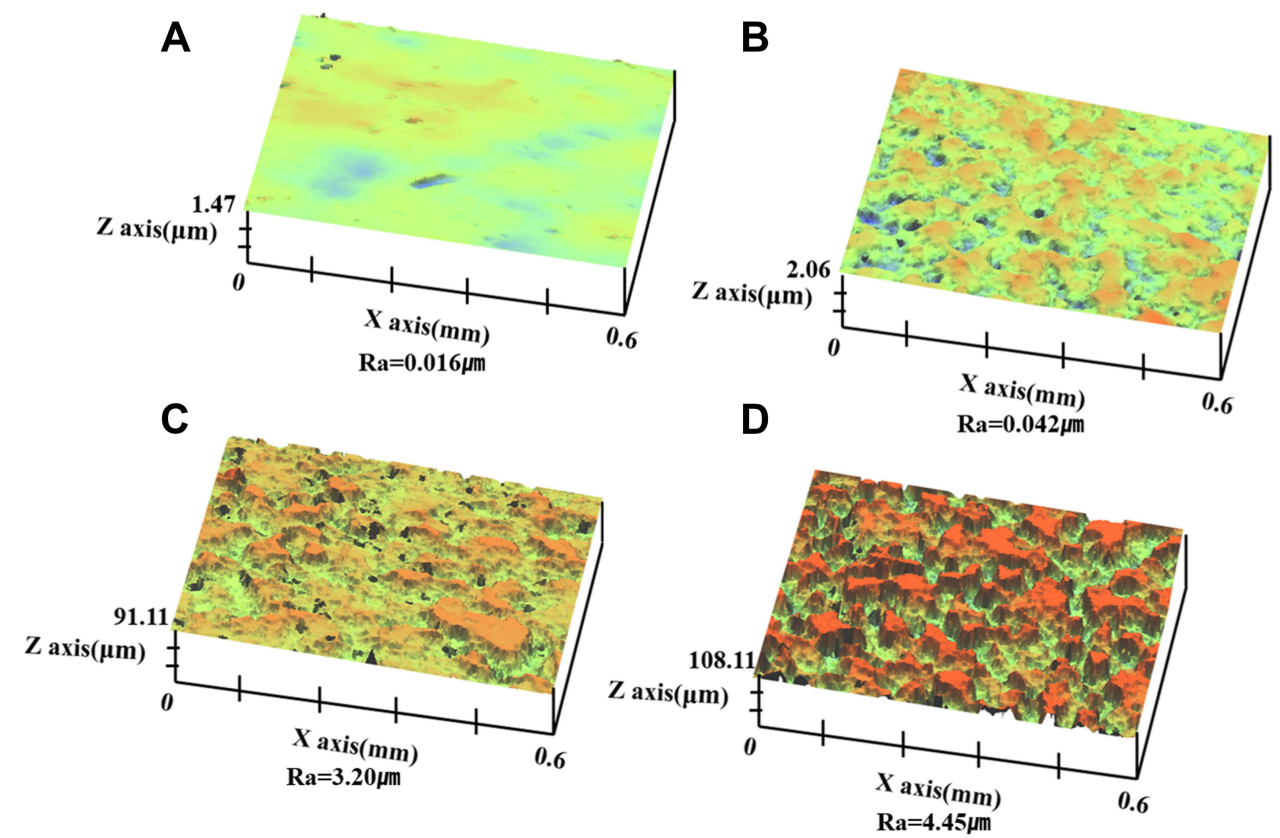

Figure 4 Three-dimensional surface morphology and roughness of the titanium samples in: (A) the control group; (B) Group N; (C) Group NA; and (D) Group NAG.

that the antibacterial activity is significantly affected by the shape and roughness of the surface, ${ }^{17}$ the porous oxide film formed on the mulberry surface in Group NA increases the surface area of the sample, ${ }^{18}$ whereas the graphene oxide deposition in Group NAG further increases the antibacterial activity. 

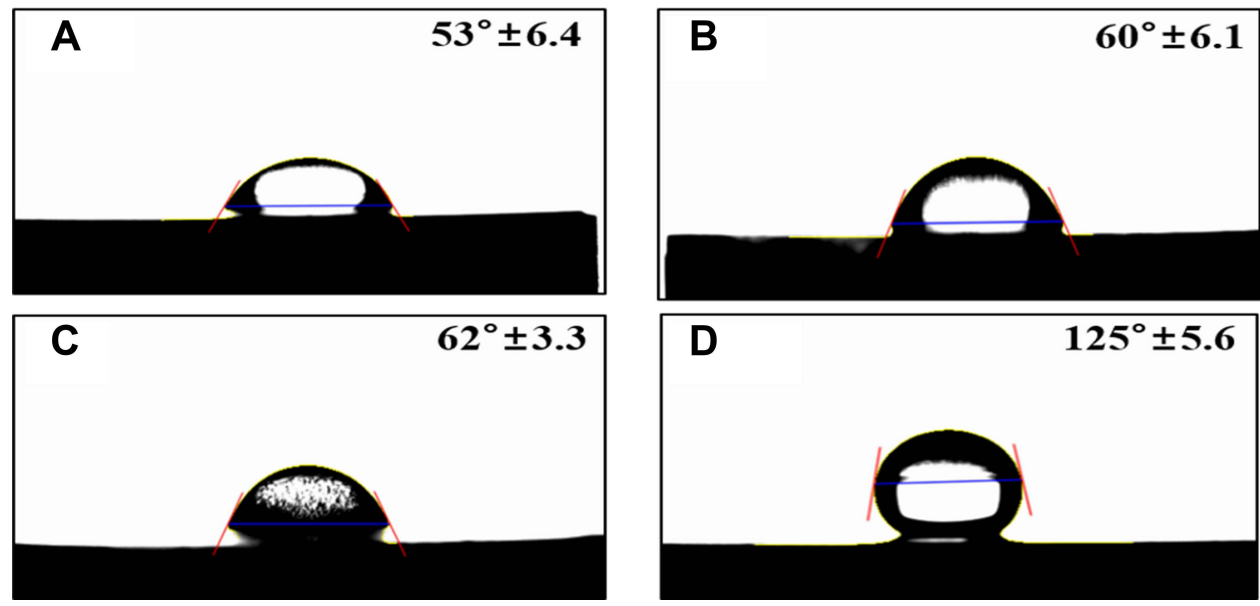

Figure 5 Water contact angle measurements for the titanium samples in: (A) the control group; (B) Group N; (C) Group NA; and (D) Group NAG.

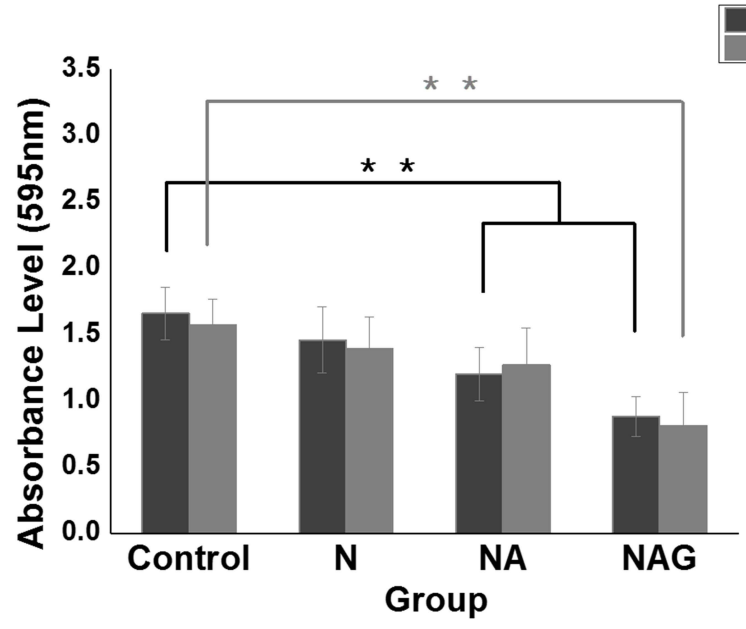

Figure 6 Results of a one-way ANOVA test to analyze the adhesion of Streptococcus mutans (S.M) and Porphyromonas gingivalis (P.G) to the titanium samples in the control group and groups N, NA, and NAG. **Marginally significant at $p<0.00 \mathrm{I}$.

\section{Osteoblast Activation}

\section{Cell Adhesion/Proliferation}

The adhesion of MC3T3-E1 cells was analyzed using a WST assay after culturing the cells for $24 \mathrm{~h}$. The adhesion of cells to the surfaces of groups N, NA, and NAG was significantly higher than the adhesion in the control group, showing that all three experimental groups had higher cell activity than the control. Cell proliferation was analyzed using a WST assay after culturing the cells for five days. A significant increase in cell proliferation was observed in groups N and NA compared to that in the control group, while group NAG exhibited the highest cell activity (Figure 7). An image of fluorescently stained cells attached to the surface is shown in (Figure 8). Cells were uniformly dispersed on each supporter after 1 day of

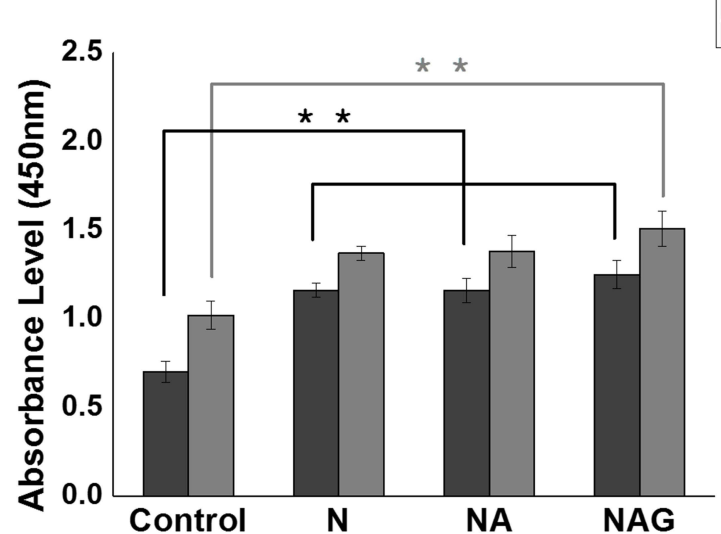

Figure 7 Results of one-way ANOVA tests for the WST assays conducted on cells cultured for either $24 \mathrm{~h}$ or 5 days on the titanium samples in the control group and groups N, NA, and NAG. **Marginally significant at $p<0.00 \mathrm{I}$.

incubation. In particular, the cell density showed a welldispersed form after 5 days of incubation, and as the incubation time increased, the cell density increased, indicating that all of the surface-treated experimental groups provided a favorable environment for cell adhesion and proliferation.

\section{Cellular Differentiation}

The differentiation of MC3T3-E1 cells was analyzed using an ALP assay after culturing the cells for seven days. A substantial increase in cell differentiation was observed in group NAG compared to that in the control group and group N (Figure 9). Figure 10 presents a comparison of the cell viability and antibacterial effects of the different titanium surfaces. Cell viability increased gradually with the addition of surface treatments, while the reverse trend was observed for the antibacterial effect. The cell viability of 


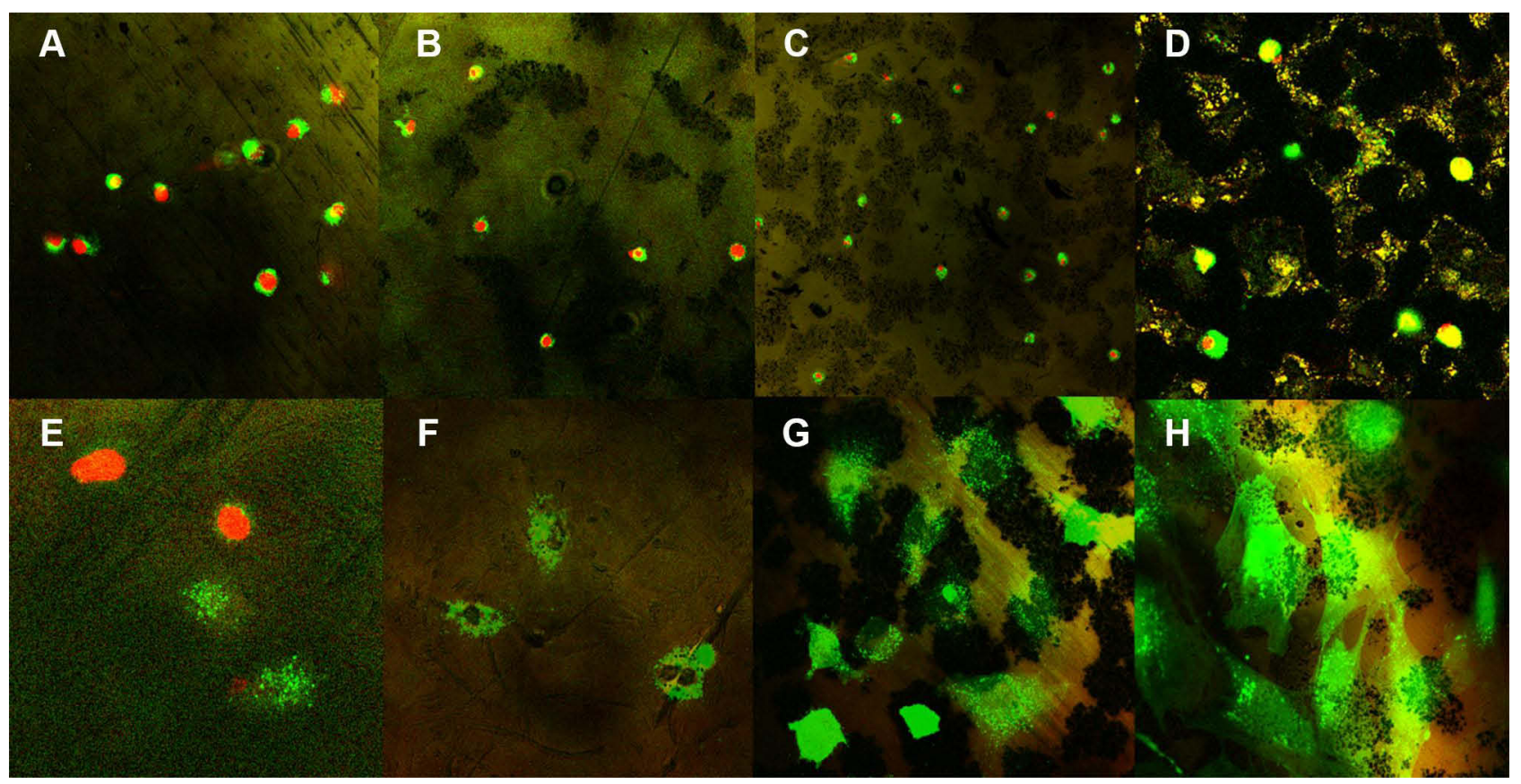

Figure 8 Fluorescent staining images of cells cultured for either 24 h (64× confocal laser scanning microscope mode). (A) the control group; (B) Group N; (C) Group NA; and (D) Group NAG. Fluorescent staining images of cells cultured for either 5 days (I28x confocal laser scanning microscope mode). (E) the control group; (F) Group N; (G) Group NA; and (H) Group NAG. Green fluorescence indicates viable cells and red fluorescence indicates dead cells.

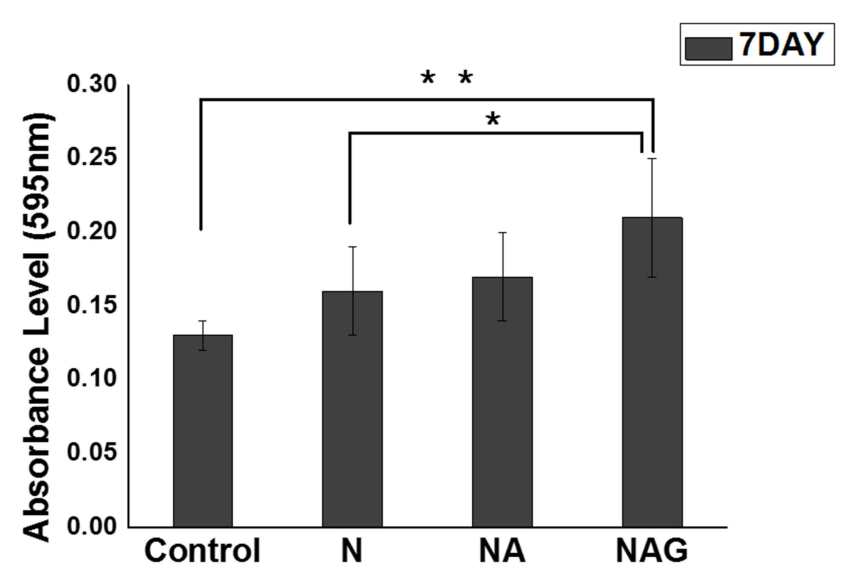

Figure 9 Results of a one-way ANOVA test for cells cultured for 7 days on titanium samples in the control group and groups N, NA, and NAG and measured with an ALP assay. *Marginally significant at $p<0.05$, **Marginally significant at $p<0.001$.

group NAG was enhanced by $45 \%$, while its bacterial activity was reduced by $60 \%$ compared to that of the control (ie, without any surface treatment).

\section{Discussion}

Titanium has been widely used in dentistry as a successful implant material because of its high biocompatibility. ${ }^{19}$ In addition, surfaces with both micropores and nanopores have been reported to maximize the contact between the osseous tissues and the implant, improve osseointegration, and inhibit

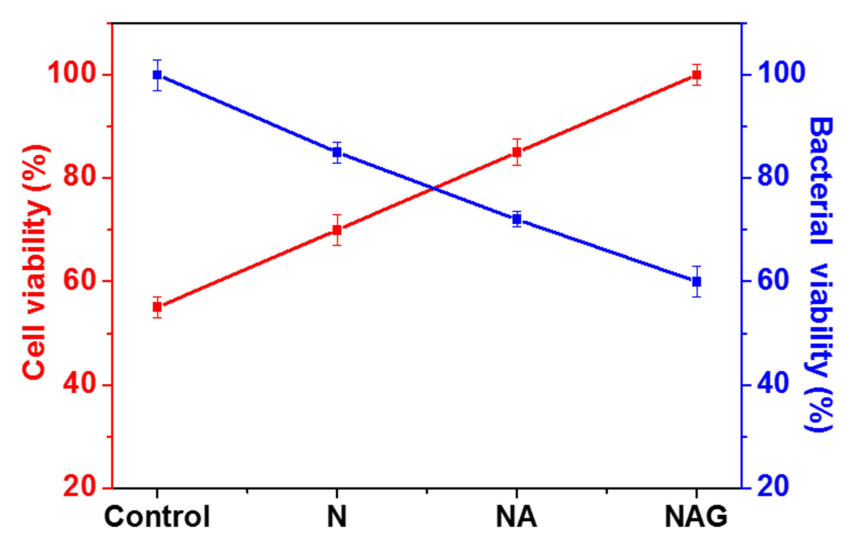

Figure 10 Comparison of the cell viabilities and antibacterial effects among the titanium control group and groups N, NA, and NAG.

bacterial adhesion and biofilm formation. ${ }^{20-22}$ Considering these two factors, a titanium surface that has both micropores and nanopores can be formed by performing electrochemical treatments, such as anodic oxidation, while the shape of the surface can be modified by controlling the process variables, such as electrolyte composition, voltage, and temperature. ${ }^{23}$

Graphene oxide, which is a nanomaterial with biological properties, has also been applied to dental implants because of its antibacterial activity and properties related to cell adhesion, proliferation, and differentiation. However, its production also has several disadvantages, such as low accessibility, high cost, and the generation of harmful 
gases leading to pollution. ${ }^{13-15}$ These issues can be addressed by using an atmospheric plasma-based method, which is simple to execute and can mass-produce graphene oxide continuously. ${ }^{24}$ Therefore, in this study, we developed a novel approach for depositing graphene oxide using atmospheric plasma and found that it significantly promotes cell differentiation. ${ }^{16}$ In this study, both nitriding and anodic oxidation were performed on the titanium surface to achieve the roughness of the mulberry surface that contains both micropores and nanopores. Moreover, graphene oxide was deposited on this surface to utilize its properties related to the inhibition of bacterial adhesion and those related to the adhesion, proliferation, and differentiation of osteoblasts.

The surface roughness was measured using 3D-OP analysis, and the roughness value was observed to be higher in groups NA and NAG than in the control group and group N. It has been reported that the higher the surface roughness, the sharper the surface is, and thus, inhibition of bacterial adhesion is better in such cases. $^{25}$ In addition, studies on the mechanism of antibiosis have reported that graphene oxide primarily inhibits bacterial adhesion through oxidative stress of and direct bacterial contact with its sharp surface. ${ }^{26-28}$ Consistent with the above findings, in this study, we also observed that the titanium surface treated with anodic oxidation and graphene oxide deposition became rougher and sharper, which in turn increased the inhibition of bacterial adhesion. The wettability of the surface was tested by measuring the water contact angle, and we observed that the control group and groups $\mathrm{N}$ and NA showed a hydrophilic tendency. In contrast, group NAG showed a hydrophobic tendency. Many studies have been conducted on the association of inhibition of bacterial adhesion with the surface properties. For instance, Agarwalla et $\mathrm{al}^{29}$ studied the inhibitory effect of a surface treated with graphene oxide deposition on $S$. mutans They reported that the resulting hydrophobic surface increased the inhibition of bacterial adhesion. Our findings are in agreement with these results.

Several recent studies have reported increases in the antimicrobial activity of graphene oxide depositions. ${ }^{26,30,31}$ A report demonstrated that graphene oxide deposition reduced the thickness of the biofilm formed by Pseudomonas putida and increased the ability to separate the biofilm from the surface. ${ }^{32}$ The mechanism of antimicrobial activity of graphene oxide deposition has not yet been clearly determined, and research is still ongoing. The known antibacterial mechanism of graphene oxide deposition has been reported to have two causes: oxidative stress on graphene oxide deposition and inhibition of bacterial adhesion caused by direct contact with sharp edges of graphene oxide deposition. ${ }^{33-35}$ In other words, it is considered that the surface on which anodic oxidation and graphene oxide deposition are applied becomes rougher and the edges become sharper, resulting in an increase in the ability to inhibit bacterial adhesion. Contrary to these arguments, however, some studies have performed relevant in vitro experiments, which suggest that the ROS mechanism is not the primary mechanism for the antimicrobial action of graphene oxide deposition. $^{36,37}$ Another antimicrobial process involves the dispersibility and entrapment ability of oxygencontaining functional groups in graphene oxide deposition. ${ }^{38,39}$ It has been reported that graphene oxide depositions with hydrophobic functional groups exert antibacterial property by forming a stable dispersion and providing a large contact area to interact with bacterial cells. Experiments and discussions are ongoing to study the antimicrobial effect of graphene oxide depositions and the effect of functional groups and such effects should be studied and examined more closely in the future.

In terms of cell activity, Sagirkaya et $\mathrm{al}^{33}$ reported that cell adhesion levels varied depending on the surface roughness of the materials, their chemical composition, and the size of the pores. Zhang et $\mathrm{al}^{34}$ reported that a porous oxide film, containing micropores and nanopores on the titanium surface, had a positive impact on the adhesion and stabilization of cells. In addition, Park et $\mathrm{al}^{35}$ reported that a surface with nanopores in the size range of 15-30 $\mathrm{nm}$ facilitates the adhesion of various types of cells, including osteoblasts. Several studies, including Ekaterina, ${ }^{40,41}$ have shown that osteoblasts recognize surface roughness through the interaction of proteins in the extracellular matrix and that they react to grooves that are $100 \mathrm{~nm}$ or less in size. It is worth noting that the size of the integrin molecules that exist in osteoblasts is similar to that of the nano-sized grooves formed on the implant surface. Hence, the adhesion of osteoblasts seemed to increase in group NA, which had nanopores, compared to that of the control group in this study.

Previous studies have reported that graphene oxide has good biocompatibility and plays a biological role in promoting osteogenic adhesion, proliferation, differentiation, and calcium mineral deposition. ${ }^{42-44}$ Deposited graphene oxide sheets have numerous negatively charged oxygencontaining functional groups, which can interact with cell 
membrane phospholipids and proteins through electrostatic interactions, hydrogen bonding, etc. Such interactions allow osteoblasts to attach to deposited graphene oxide sheets and then proliferate. ${ }^{45}$ The excellent surface properties of graphene oxide depositions lead to the adsorption of some bioactive ions and proteins on them, which promotes diffusion of cytoskeletal actin filaments into the matrix and further stimulates osteogenic differentiation. $^{46}$ It was found that the integration of micro- and nano-structured surfaces and graphene oxide deposition system provide a microenvironment suitable for osteogenic differentiation of cells. Therefore, the surface properties were significantly changed due to graphene oxide deposition, further promoting osteogenic differentiation.

The adhesion, proliferation, and differentiation of osteoblasts also increased in group NAG, which was treated with graphene oxide, and these results can be attributed to the aforementioned characteristics of graphene oxide. ${ }^{47}$

This study confirmed that titanium implants with mulberry surface (ie, having both micropores and nanopores) and a layer of graphene oxide effectively inhibit bacterial adhesion and increase the activity of osteoblasts.

\section{Conclusions}

The formation of mulberry surface on titanium implants as a result of nitriding and anodic oxidation was studied, and graphene oxide was deposited on this surface. We observed that bacterial adhesion was inhibited, while the adhesion, proliferation, and differentiation of osteoblasts were enhanced on this surface. Therefore, we conclude that titanium implants with mulberry surface and graphene oxide deposition can reduce peri-implantitis and improve osseointegration.

\section{Funding}

This work was supported by a National Research Foundation of Korea (NRF) grant funded by the Korean government (MSIP) (No. 2020R1F1A1076982 and 2018R1A6A1A03024334).

\section{Disclosure}

Hee-Seon Kim, Min-Kyung Ji, and Woo-Hyung Jang are cofirst auhtors. Miss Hee-Sun Kim reports grants from National Research Foundation of Korea (2020R1F1A1076982, 2018R1A6A1A030243340 during the conduct of the study. The authors report no conflicts of interest in this work.

\section{References}

1. Yeo ISL. Modifications of dental implant surfaces at the micro-and nano-level for enhanced osseointegration. Materials. 2020;13(1):89. doi:10.3390/ma13010089

2. Parnia F, Yazdani J, Javaherzadeh V, Dizaj SM. Overview of nanoparticle coating of dental implants for enhanced osseointegration and antimicrobial purposes. J Pharm Pharm Sci. 2017;20:148-160. doi:10.18433/J3GP6G

3. Lee MJ, Kwon JS, Jiang HB, Choi EH, Park G, Kim KM. The antibacterial effect of non-thermal atmospheric pressure plasma treatment of titanium surfaces according to the bacterial wall structure. Sci Rep. 2019;9(1):1-13. doi:10.1038/s41598-019-39414-9

4. Albrektsson T, Wennerberg A. On osseointegration in relation to implant surfaces. Clin Implant Dent Relat Res. 2019;21(S1):4-7. doi:10.1111/cid.12742

5. Ji MK, Park SW, Lee KM, et al. Evaluation of antibacterial activity and osteoblast-like cell viability of $\mathrm{TiN}, \mathrm{ZrN}$ and (Ti1-xZrx) N coating on titanium. J Adv Prosthodont. 2015;7(2):166-171. doi:10.4047/jap.2015.7.2.16

6. Ji MK, Lee MJ, Park SW, et al. Evaluation of antibacterial activity of titanium surface modified by PVD/PACVD process. J Nanosci Nanotechnol. 2016;16(2):1656-1659. doi:10.1166/ jnn.2016.11924

7. Seo NR, Ji MK, Park SW, et al. Effect on adhesion of Porphyromonas gingivalis by titanium nitride sputter coating or plasma nitriding of titanium. J Nanosci Nanotechnol. 2017;17 (4):2633-2636. doi:10.1166/jnn.2017.13320.2633

8. Mahdy EA, Sahbal KM, Mabrouk M, Beherei HH, AbdelMounem YK. Enhancement of glass-ceramic performance by $\mathrm{TiO} 2$ doping: in vitro cell viability, proliferation, and differentiation. Ceram Int. 2021;47(5):6251-6261. doi:10.1016/j. ceramint.2020.10.203

9. Ellingsen JE, Johansson CB, Wennerberg A, et al. Improved retention and bone-to-implant contact with fluoride-modified titanium implants. Int J Oral Maxillofac Implants. 2004;19(5). doi:10.1016/j. apsusc.2013.02.036

10. Necula BS, Apachitei I, Fratila-Apachitei LE, et al. Titanium bone implants with superimposed micro/nano-scale porosity and antibacterial capability. Appl Surf Sci. 2013;273:310-314. doi:10.1016/j. apsusc.2013.02.036

11. Su EP, Justin DF, Pratt CR, et al. Effects of titanium nanotubes on the osseointegration, cell differentiation, mineralisation and antibacterial properties of orthopaedic implant surfaces. Bone Jt J. 2018;100 (1_Supple_A):9-16. doi:10.1302/0301-620X.100B1

12. Sali S, Mackey HR, Abdala AA. Effect of graphene oxide synthesis method on properties and performance of polysulfone-graphene oxide mixed matrix membranes. Nanomaterials. 2019;9(5):769. doi:10.3390/nano9050769

13. Alam K, Jo YY, Park CK, Cho H. Synthesis of graphene oxide using atmospheric plasma for prospective biological applications. Int J Nanomedicine. 2020;15:5813. doi:10.2147/IJN.S254860

14. Yi M, Shen Z. A review on mechanical exfoliation for the scalable production of graphene. J Mater Chem. 2015;3(22):11700-11715. doi:10.1039/c5ta00252d

15. Lambert TN, Luhrs CC, Chavez CA, et al. Graphite oxide as a precursor for the synthesis of disordered graphenes using the aerosol-through-plasma method. Carbon. 2010;48(14):4081-4089. doi:10.1016/j.carbon.2010.07.015

16. Rho K, Park C, Alam K, et al. Biological effects of plasma-based graphene oxide deposition on titanium. J Nanomater. 2019;2019:1-7. doi:10.1155/2019/9124989

17. Quirynen M, Bollen CML. The influence of surface roughness and surface-free energy on supra-and subgingival plaque formation in man: a review of the literature. J Clin Periodontol. 1995;22 (1):1-14. doi:10.1111/j.1600-051X.1995.tb01765.x 
18. Lavenus S, Louarn G, Layrole P. Nanotechnology and dental implants. Int J Biomater. 2010;2010:1-9. doi:10.1155/2010/915327

19. Persson LG, Berglundh T, Lindhe J, Sennerby L. Re-osseointegration after treatment of peri-implantitis at different implant surfaces: an experimental study in the dog. Clin Oral Implants Res. 2001;12 (6):595-603. doi:10.1034/j.1600-0501.2001.120607

20. Anil S, Anand PS, Alghamdi H, Jansen J. A Dental implant surface enhancement and osseointegration. In: Implant Dentistry - a rapidly Evolving Practice. 2001:83-108. doi:10.5772/16475

21. Vandrovcová M, Bacakova L. Adhesion, growth and differentiation of osteoblasts on surface-modified materials developed for bone implants. Physiol Res. 2011;60(3):403. doi:10.33549/physiolres.932045

22. Tsukimura N, Yamada M, Iwasa F, et al. Synergistic effects of UV photofunctionalization and micro-nano hybrid topography on the biological properties of titanium. Biomaterials. 2011;32 (19):4358-4368. doi:10.1016/j.biomaterials.2011.03.001

23. Tsuchiya H, Macak JM, Taveira L, et al. Self-organized $\mathrm{TiO}_{2}$ nanotubes prepared in ammonium fluoride containing acetic acid electrolytes. Electrochem Commun. 2005;7(6):576-580. doi:10.10 16/j.elecom.2005.04.008

24. Phillips J, Luhrs CC, Richard M. Engineering particles using the aerosol-through-plasma method. IEEE Plasma Sci. 2009;37 (6):726-739. doi:10.1109/TPS.2009.2016969

25. Ordikhani F, Farani MR, Dehghani M, et al. Physicochemical and biological properties of electrodeposited graphene oxide/chitosan films with drug-eluting capacity. Carbon. 2015;84:91-102. doi:10.10 16/j.carbon.2014.11.052

26. Zou X, Zhang L, Wang Z, et al. Mechanisms of the antimicrobial activities of graphene materials. $J$ Am Chem Soc. 2016;138 (7):2064-2077. doi:10.1021/jacs.5b11411

27. Akhavan O, Ghaderi E. Toxicity of graphene and graphene oxide nanowalls against bacteria. ACS Nano. 2010;4(10):5731-5736. doi:10.1021/nn101390x

28. Gurunathan S, Han JW, Dayem AA, et al. Oxidative stress-mediated antibacterial activity of graphene oxide and reduced graphene oxide in Pseudomonas aeruginosa. Int J Nanomed. 2012;7:5901. doi:10.2147/ IJN.S37397

29. Agarwalla SV, Ellepola K, da Costa MCF, et al. Hydrophobicity graphene as a driving force for inhibiting biofilm formation of pathogenic bacteria and fungi. Dent Mater. 2019;35(3):403-413. doi:10. 1016/j.dental.2018.09.016

30. Qian W, Wang Z, He D, et al. Ornidazole-loaded graphene paper for combined antibacterial materials. J Saudi Chem Soc. 2018;22 (5):581-587. doi:10.1016/j.jscs.2017.10.002

31. Qiu JJ, Geng H, Wang DH, et al. Layer-number dependent antibacterial and osteogenic behaviors of graphene oxide electrophoretic deposited on titanium. ACS Appl Mater Interfaces. 2017;9 (14):12253-12263. doi:10.1021/acsami.7b00314

32. Fallatah H, Elhaneid M, Ali-Boucetta H, Overton TW, El Kadri H, Gkatzionis K. Antibacterial effect of graphene oxide (GO) nano-particles against Pseudomonas putida biofilm of variable age. Environ Sci Pollut Res Int. 2019;26(24):25057-25070. doi:10.1007/ s11356-019-05688-9
33. Sagirkaya E, Kucukekenci AS, Karasoy D, et al. Comparative assessments, meta-analysis, and recommended guidelines for reporting studies on histomorphometric bone-implant contact in humans. Int $J$ Oral Maxillofac Implants. 2013;28(5). doi:10.1016/j.dental.2018.09.016

34. Zhang L, Zhu S, Han Y, Xiao C, Tang W. Formation and bioactivity of HA nanorods on micro-arc oxidized zirconium. Mater Sci Eng C Mater Biol Appl. 2014;43:86-91. doi:10.1016/j.msec.2014.06.029

35. Park J, Bauer S, Schlegel KA, Neukam FW, van der Mark K, Schmuki P. TiO2 nanotube surfaces: $15 \mathrm{~nm}$-an optimal length scale of surface topography for cell adhesion and differentiation. Small. 2009;5(6):666-671. doi:10.1002/smll.200801476

36. Jaworski S, Wierzbicki M, Sawosz E, et al. Graphene oxide-based nanocomposites decorated with silver nanoparticles as an antibacterial agent. Nanoscale Res Lett. 2018;13(1):1-17. doi:10.1186/s11671-018-2533-2

37. Zhao M, Shan T, Wu Q, Gu L. The Antibacterial Effect of Graphene Oxide on Streptococcus mutans. J Nanosci Nanotechnol. 2020;20 (4):2095-2103. doi:10.1166/jnn.2020.17319

38. Xie YY, Hu XH, Zhang YW, et al. Development and antibacterial activities of bacterial cellulose/graphene oxide- $\mathrm{CuO}$ nanocomposite films. Carbohydr Polym. 2020;229:115456. doi:10.1016/j.carbpol.2019.115456

39. Xue J, BinAhmed S, Wang Z, Karp NG, Stottrup BL, Castrillon SRV. Bacterial adhesion to graphene oxide (GO)-functionalized interfaces is determined by hydrophobicity and GO sheet spatial orientation. Environ Sci Technol Lett. 2018;5(1):14-19. doi:10.1021/acs.estlett.7b00509

40. Gongadze E, Kabaso D, Bauer S, et al. Adhesion of osteoblasts to a nanorough titanium implant surface. Int J Nanomed. 2011;6:1801. doi:10.2147/ijn.s21755

41. Lamers E, Walboomers XF, Domanski M, et al. The influence of nanoscan grooved substrates on osteoblast behavior and extracellular matrix deposition. Biomaterials. 2010;31(12):3307-3316. doi:10.10 16/j.biomaterials.2010.01.034

42. Liang C, Luo Y, Yang G, et al. Graphene oxide hybridized nHAC/ PLGA scaffolds facilitate the proliferation of MC3T3-E1 cells. Nanoscale Res Lett. 2018;13(1):15. doi:10.1186/s11671-018-2432-6

43. Raucci MG, Giugliano D, Longo A, Zeppetelli S, Carotenuto G, Ambrosio L. Comparative facile methods for preparing graphene oxide-hydroxyapatite for bone tissue engineering. J Tissue Eng Regen Med. 2016;11(8):2204-2216. doi:10.1002/term.2119

44. Wang Y, Hu XX, Jing D, et al. A 3D graphene coated bioglass scaffold for bone defect therapy based on molecular targeting approach. J Mater Chem. 2017;5:6794-6800. doi:10.1039/C7TB01515A

45. Yan F, Liu Z, Zhang T, et al. Biphasic injectable bone cement with Fe3O4/GO nanocomposites for the minimally invasive treatment of tumor-induced bone destruction. ACS Biomater Sci Eng. 2019;5 (11):5833-5843. doi:10.1021/acsbiomaterials.9b00472

46. Ren N, Li J, Qiu J, et al. Growth and accelerated differentiation of mesenchymal stem cells on graphene-oxide-coated titanate with dexamethasone on surface of titanium implants. Dent Mater. 2017;33 (5):525-535. doi:10.1016/j.dental.2017.03.001

47. Xie H, Cao T, Rodríguez-Lozano FJ, Rosa V. Graphene for the development of the next-generation of biocomposites for dental and medical applications. Dent Mater. 2017;33(7):765-774. doi:10.1016/ j.dental.2017.04.008
International Journal of Nanomedicine

\section{Publish your work in this journal}

The International Journal of Nanomedicine is an international, peerreviewed journal focusing on the application of nanotechnology in diagnostics, therapeutics, and drug delivery systems throughout the biomedical field. This journal is indexed on PubMed Central, MedLine, CAS, SciSearch ${ }^{\mathbb{R}}$, Current Contents $^{\mathbb{B}} /$ Clinical Medicine, $^{2}$
Journal Citation Reports/Science Edition, EMBase, Scopus and the Elsevier Bibliographic databases. The manuscript management system is completely online and includes a very quick and fair peer-review system, which is all easy to use. Visit http://www.dovepress.com/ testimonials.php to read real quotes from published authors. 